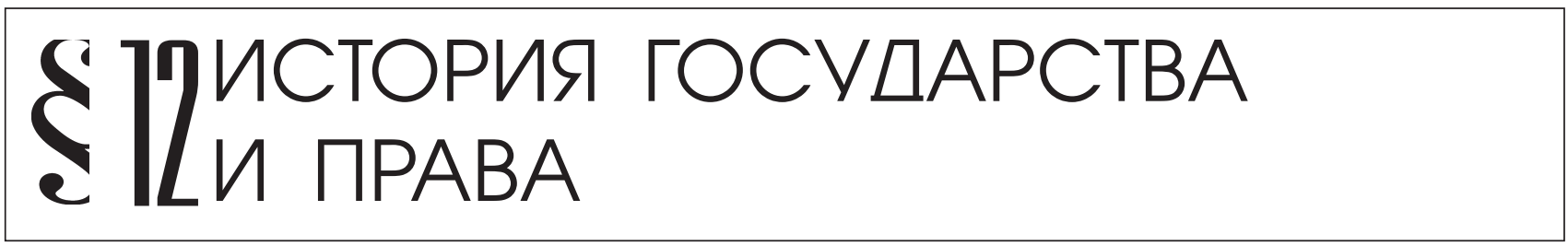

Пыльцина М.B.

\title{
УЧРЕЖДЕНИЕ ДЕПАРТАМЕНТА ЗЕМЛЕДЕЛИЯ В США - ПОИСК ОРГАНИЗАЦИОННО-ПРАВОВЫХ ОСНОВ УПРАВЛЕНИЯ СЕЛЬСКИМ ХОЗЯЙСТВОМ
}

Аннотация: Предметом данного исследования является исторический опыт учреждения Департамента земледелия в США, на который была возложена основная роль в выработке стратегии развития сельского хозяйства и регулировании аграрных отношений. Его роль в повышении эффективности земледелия, трансляции научного знания в фермерскую среду являлась одной из важнейших в аграрных преобразованиях страны второй половины ХІХ в., не утратившая к тому же своей актуальности и сегодня. Особое внимание уделяется идеям Дж. Вашингтона, чьи теоретические и практические изыскания сформировали в последующем представление о роли административных сельскохозяйственных учреждений в развитии аграрного сектора экономики. Подчеркивается, что вплоть до появления Департамента земледелия состояние фермерских хозяйств в хозяйственном отношении во многом зависело от инициатив сельскохозяйственных обществ как института гражданского общества. В ходе исследования применялись исторический, проблемно-хронологический и сравнительный методы, которые позволили провести анализ различных подходов к реформированию сложивиейся сельскохозяйственной системы. Особым вкладом автора в исследование темы является попьтка реконструировать процесс поиска путей оптимизации управления сельским хозяйством. Так как приоритетным направлением деятельности Департамента земледелия являлась реализация научно-практических проектов в сфере сельского хозяйства, делается вывод о схожести данного учреждения с Сельскохозяйственным советом Министерства земледелия и государственных имущзеств Российской империи.

Ключевые слова: История, право, сельское хозяйство, Департамент земледелия, административная реформа, аграрная политика, аграрные проекты, общественная инициатива, Дж. Вашингтон, США.

Abstract: The subject of this research is the historical experience of the establishment of the US department of agriculture, which was tasked with devising a strategy for developing the farming industry and regulating the agricultural relations. Its role in increasing the efficiency offarming and transference of scientific knowledge onto the farming environment became one of its most important roles in agricultural transformations of the country in the second half of the XIX century, and still maintains its relevance even today. A special attention is given to the ideas of George Washington, who's theoretical and practical findings later formed the understanding of the role of the administrative agricultural establishments in development of the agricultural sector of the economy. The author's contribution into the research of this topic is the attempt to reconstruct the process of the search for ways to optimize the administration of farming and agriculture. Since the primary direction of the work of the USDA is the implementation of scientific and practical projects in the area of agriculture, the author concludes that there are similarities between this department and the Ministry of Cultivation and State Property of the Russian Empire. Keywords: Agricultural projects, agricultural policy, administrative reform, agriculture department, agriculture, law, history, public initiative, George Washington, US.

опросы организации и деятельности сельскохозяйственных учреждений за рубежом, несмотря на актуальность и значимость исследований по подобной проблематике, неполно отражены в отечественной историко-правовой на- уке. Явная недостаточность источников создает сложности в изучении данной темы. Аграрный опыт иностранных государств, и в частности США, тем более интересен, что в настоящее время сельское хозяйство, от которого зависит продовольственная 
DOI: $10.7256 / 1811-9018.2015 .11 .14653$

При цитировании этой статьи сноска на dоі обязательна

\section{Право и политика $11(191) \cdot 2015$}

безопасность страны, стало заложником политических спекуляций.

В середине XIX в. Соединенные Штаты представляли собой аграрную страну. Освоение новых территорий на Западе, принятие закона о гомстедах в 1862 г., исход Гражданской войны 1861-1865 гг. способствовали развитию сельского хозяйства по капиталистическому пути. Соединенные Штаты ранее европейских государств признали важнейшей основой экономического расцвета не только политическую свободу, но и экономический либерализм [1, с. 134].

Несмотря на то, что первые ведомства в Соединенных Штатах - департаменты - появились еще в 1780-1790-х гг., высший же правительственный сельскохозяйственный орган на правах министерства - Департамент земледелия - был учрежден только в 1862 г. Отметим, что данное министерство прошло длительный путь своего становления, и его учреждение было обусловлено прежде всего развитием рационализаторских идей в области сельского хозяйства.

У истоков учреждения Департамента земледелия стоял основатель государства, первый президент Соединенных Штатов Джордж Вашингтон. Будучи плантатором и экспериментируя с новыми методами возделывания пшеницы, ячменя, табака, овса, он стремился побудить плантаторов к ведению хозяйства с использованием агрономических новаций, к реализации творческой и общественной активности.

На формирование аграрного мировоззрения Вашингтона повлияли взгляды английских ученыхагрономов XVIII в. Артура Юнга и Джона Синклера, переписка с которыми велась им на протяжении длительного времени. Осознавая тесную зависимость экономического развития страны от уровня просвещения, Вашингтон «выписал из Англии кучу книг, касавшихся агротехники, особо выделив труд «Система сельского хозяйства или быстрый способ разбогатеть»» [2, с. 97].

В свете господствующих идей физиократов свой взгляд на земледелие Вашингтон выразил в следующих словах: «Земледелие имеет первостепенное значение в отношении как частного, так и общественного благосостояния ...» [3, с. 254], подтверждая американскую пословицу: «есть деньги у фермера, есть они у всех». «Земледелие всегда было любимым моим занятием, - писал он после революции, - и я все более и более привязываюсь к земледельческим делам; я думаю, что неиспорченному человеку несравненно приятнее совершенствовать свое полевое хозяйство, чем вся та пустая слава, какую можно приобрести опустошением земли, хотя бы одерживая непрерывные победы» [4, с. 6].
Его сельскохозяйственный интерес не ограничивался исключительно вопросами земледелия: достаточное внимание уделялось садоводству как одной из доходных отраслей сельского хозяйства. Практическая сторона деятельности Вашингтона включала в себя разведение фруктовых деревьев, оранжерей, приобретение в Европе и Вест-Индии экзотических видов растений.

Соединение опыта государственного деятеля и агронома-практика позволило Вашингтону разработать сельскохозяйственный проект, занимающий особое место в аграрной истории США, и осуществить который он надеялся в два этапа. По его замыслу сначала должны были появиться земледельческие общества малого района действия, образовав, таким образом, сеть сельскохозяйственных структур, и только затем федеральный сельскохозяйственный орган, призванный обеспечить единство всех аграрных организаций и выступить в роли посредника между правительством и обществом. Руководящая идея проекта сводилась к постепенности его осуществления, и, что самое важное, на наш взгляд, с опорой на общественные силы.

Проект был близок к тому, чтобы стать действительностью. Тем не менее, Конгресс, опираясь на предложения Вашингтона, все же решил пойти по пути создания Особой комиссии, которая должна была рассмотреть вопрос об учреждении Высшего правительственного учреждения по сельскохозяйственной части. Члены комиссии, изучив прежде всего соответствующее английское законодательство, констатировали о желательности учреждения в республике Центрального земледельческого общества. В начале 1797 г. проект, несмотря на всю тщательность его разработки, по целому ряду причин объективного характера так и не был утвержден Конгрессом.

Вместе с тем интерес к дальнейшему усовершенствованию сельского хозяйства не ослабевал, что нашло выражение в появлении экономических и сельскохозяйственных организаций. Так, в 1806 г. было учреждено Общество для развития народной экономии, в 1809 г. - Колумбийское земледельческое общество, представляющее местные союзы фермеров. Однако их деятельность по оптимизации аграрной сферы находилась еще в зачаточном состоянии и носила, скорее, случайный характер.

Первые десятилетия XIX в. в Соединенных Штатах ознаменовались крайне ограниченным производством хлеба, неравномерностью развития сельского хозяйства в отдельных штатах. На последнее обстоятельство указывал неизвестный автор статьи «Меньше хлопка! Больше продовольственных культур!», опубликованной 
в 1827 г. в газете «Курьер». В статье подчеркивалось, что, несмотря на благоприятные климатические условия и плодородные почвы южных штатов, отчетливо прослеживается зависимое в сельскохозяйственном отношении их положение от северных штатов. Касаясь отсталости агротехнической составляющей фермерского хозяйства южных штатов, сосредоточения труда и капитала на хлопковой отрасли промышленности, автор предлагал меры для искоренения этого недостатка: «пусть наши фермеры [южных итатов - авт.] изготовляют и носят свои домотканые одежды, выращивают в изобилии кукурузу и пшеницу, что даст им возможность разводить свиней, рогатый скот и лошадей, и пусть те, у которых есть средства, займутся производством в более широком масштабе» [5, с. 157-158].

Оживление интереса к введению прогрессивных форм организации сельского хозяйства было вызвано крупным неурожаем, разразившимся в 1837-1838 гг. и повлекшим за собой аграрный кризис. Отмечая бесспорное влияние практических мероприятий на повышение доходности фермерских хозяйств, Генри Ливитт Эллсуорт, уполномоченный бюро Патентов при Государственном Департаменте, начал распространять среди населения улучшенные сорта растений.

Конгресс, признавая возможный риск агрикультурных нововведений и указывая на его нивелирование путем организации надлежащего руководства, не только выделил единовременные ассигнования на аграрные мероприятия, но и в рамках Патентного бюро создал Сельскохозяйственное подразделение, для которого реализация аграрно-просветительских проектов являлась основной и важнейшей. Поэтому заслуженно Сельскохозяйственный центр Эллсуорта часто называют «отцом» Министерства земледелия США.

Однако в 1849 г. Патентное бюро, а вместе с ним и Сельскохозяйственное подразделение, было передано в ведомство Министерства внутренних дел, что лишило его определенной доли самостоятельности. Таким образом, решение вопросов, относящихся к аграрному сектору, вплоть до учреждения Департамента земледелия, зависело от самодеятельных начал общественности, вылившихся в организацию сельскохозяйственных обществ в каждой земледельческой местности.

Представляется, что развитие сельского хозяйства было синхронизировано со становлением элементов гражданского общества [6, с. 188]. Став неотъемлемым фактором сельскохозяйственной жизни Америки, численность сельскохозяйственных обществ в середине 1850 -х гг. составляла около 900 , а к концу столетия их количество увеличилось более чем вдвое [7, с. 21].
На наш взгляд, бурный рост сельскохозяйственных обществ явился знаковым моментом институционализации представительства аграриев в национальном масштабе и стал частью государственной политики.

Правовой статус агрономических общественных организаций на уровне штатов и их деятельность определялись типовыми уставами, которые принимались их членами и утверждались законодательными собраниями штатов. Так, в 1841 г. Палатой представителей и Сенатом был утвержден устав для Нью-Йоркского центрального сельскохозяйственного общества, напрямую взаимодействовавшего с центральным правительством. Принципами деятельности общества являлись автономия и самоуправление, самофинансирование, выборность, некоммерческий характер деятельности.

Согласно уставу общество должно было способствовать образованию автономных от него сельскохозяйственных обществ на периферии, и, как отмечали современники, «... мы никогда не встречали фермера, который бы не принадлежал к одному или нескольким из них» [8, с. 655]. Предусматривалось и объединение сельскохозяйственных обществ в ассоциации, что регулировалось особыми актами поощрения земледелия.

В 1852 г. в Вашингтоне состоялся съезд американских сельских хозяев, на который съехались 152 представителя от 23 штатов, представлявших собой действительное выражение местных нужд. Доказательством того, до какой степени значимым было объединение общественной инициативы, служит решение съезда об учреждении в США Центрального земледельческого общества. «Ежегодные собрания этого Центрального земледельческого общества Соединенных Штатов ... были осуществлением до некоторой степени той национальной палаты земледелия, о которой мечтали Вашингтон и Синклер» [3, с. 258].

При президенте А. Линкольне государственные органы в силу необходимости были вовлечены в прямые переговоры с сельскохозяйственными производителями о радикальном изменении аграрной политики. Позволим себе привести слова Линкольна, сказанные им во время Гражданской войны и как нельзя более точно отражающие его отношение к земледелию: «Слава нашим храбрым солдатам, но только при помощи свободного земледелия Севера сецессия может быть окончательно побеждена и уничтожена» [9, с. 458].

Однако А. Линкольн, в целом придерживаясь аграрных представлений Вашингтона, все же исходил из заключения, что правительственное сельскохозяйствен- 
DOI: $10.7256 / 1811-9018.2015 .11 .14653$

При цитировании этой статьи сноска на доі обязательна

\section{Право и политика $11(191) \cdot 2015$}

ное ведомство имеет больше возможностей оказывать покровительство и поощрение «к извлечению богатств от возделывания земли» и отдельным фермерам, и общественным организациям аграрного типа, нежели общественные организации.

Согласно законодательному акту от 15 мая 1862 г. в г. Вашингтон был образован Департамент земледелия, призванный обеспечить единство общества и институтов власти в аграрной сфере, экономическую интеграцию страны. Не следует упускать из виду, что эта административная реформа - беспрецедентный шаг: она была осуществлена в период внутриполитического и экономического кризиса, вызванного Гражданской войной. Департамент земледелия через свой печатный орган ежемесячно публиковал отчет о своей деятельности, а «каким значением пользуется это новое для Америки учреждение - видно из того, что отчет его печатается в 200 т. экземпляров» [10, с. 124].

Поставив целью указать общие меры, способствующие улучшению земледелия, Департамент уже на первых заседаниях разработал программу по ее достижению: распространение хозяйственно-статистических сведений по сельскому хозяйству, предоставление «культурным хозяевам» данных, ведущих к разрешению практических вопросов по разным отраслям хозяйства, водворение новых улучшенных сортов растений. Отметим, что аналогичные функции были возложены на Сельскохозяйственный совет при Министерстве земледелия и государственных имуществ России.
Не касаясь практической деятельности Департамента земледелия, отметим лишь, что его штат был незначителен и включал Комиссара земледелия, статистика, энтомолога, химика и ботаника. С целью распространения среди лиц, интересующихся сельским хозяйством, научных и практических сведений по различным отраслям при Департаменте был открыт музей естественной истории. Обширные коллекции музея были предоставлены для осмотра всем желающим. Одним из наиболее надежных и действенных средств воздействия на фермерское население, в смысле распространения в нем усовершенствованных приемов культуры и введения в употребление новых и улучшенных сортов хозяйственных растений, как показал опыт многих стран, явились учрежденные при Департаменте лаборатория, опытный сад и ферма. Ежегодный бюджет Департамента земледелия на общие цели составлял от 150 до 160000 долларов, т.е. около 200000 руб. [3, с. 259].

Исходя из вышесказанного, можно сделать вывод о том, что в США на протяжении длительного времени делались попытки усовершенствовать государственноаграрный организм путем привлечения к сельскохозяйственной модернизации общественную инициативу. С учреждением Департамента земледелия, ставшего одним из элементов механизма правового регулирования сельскохозяйственной деятельности во второй половине XIX в., с точки зрения будущего развития был выработан целый ряд специфических «американских» методов хозяйствования.

\section{Библиография:}

1. Леви, Г. Основы экономического могущества Соединенных Штатов Америки / Г. Леви. - М. - Петроград: Книга, 1923. -142 с.

2. Яковлев, Н. Вашингтон / Н. Яковлев. - Изд. 2-е, испр. - М.: Молодая гвардия, 1976. - 411, [4] с.

3. Вешняков, В. Департамент земледелия в Соединенных Штатах / В. Вешняков // Русский вестник. - 1869. - Т. 79. - С. 252-264.

4. Чепинский, В. Джордж Вашингтон. Его жизнь, военная и общественная деятельность (1732 - 1799) / В. Чепинский. Петербург: Типография Высочайше утвержд. товарищества «Общественная польза», 1898. - 96 с.

5. Хрестоматия по истории Нового времени стран Европы и Америки. Кн. 1. Внутриполитическое развитие. Ч. 2 . ХІХ в. / сост. Д. В. Кузнецов. - Благовещенск: Изд-во БГУ, 2010. - 290 с.

6. Пыльцина, М.В. Правовой статус региональных сельскохозяйственных обществ Российской империи в первой половине ХІХ в. / М.В. Пыльцина // Вестник ВГАУ. - 2011. - Вып. 3. - С. 188-190.

7. Труды Императорского Вольного экономического общества. Т. 1. - С. - Петербург: Тип. В. Демакова, 1894. - 191, 82, 6 с.

8. Тверской, П.А. Министерство земледелия в Соединенных Штатах / П.А. Тверской // Вестник Европы. - 1895. - Вып.6. - C. 651-669.

9. Ланге, М. Авраам Линкольн и великая борьба между северными и южными американскими штатами. Перев. с нем. / М. Ланге. - С. Петербург: Типография Кукол-Яснопольского, 1867. - 474 с.

10. Стечкин, Н.Я. Северные сияния. Записки друзей России, ее державного вождя верноподданных / Н.Я. Стечкин. - Лейпциг: Тип. Бера и Германна, 1882. - 173, 93 с.

11. Бирюкович, В. Упования и сомнения / В. Бирюкович // Вестник Европы. - 1894. - Вып. 6. - С. 791-808.

12. Мижуев, П.Г. Великий раскол англосаксонской расы. Американская революция / П.Г. Мижуев. - С. - Петербург: Изд. Л.Ф. Пантелеева, 1901. - 252 с.

13. Борисенков А.А. Понятие общественной власти в современной российской конституции // Право и политика. - 2013. 13. - C. 1786 - 1795. DOI: 10.7256/1811-9018.2013.13.10371. 
DOI: $10.7256 / 1811-9018.2015 .11 .14653$

При цитировании этой статьи сноска на dоі обязательна

История государства и права

\section{References (transliterated):}

1. Levi, G. Osnovy ekonomicheskogo mogushchestva Soedinennykh Shtatov Ameriki / G. Levi. - M. - Petrograd: Kniga, 1923. - 142 s.

2. Yakovlev, N. Vashington / N. Yakovlev. - Izd. 2-e, ispr. - M.: Molodaya gvardiya, 1976. - 411, [4] s.

3. Veshnyakov, V. Departament zemledeliya v Soedinennykh Shtatakh / V. Veshnyakov // Russkii vestnik. - 1869. - T. 79. - S. 252-264.

4. Chepinskii, V. Dzhordzh Vashington. Ego zhizn', voennaya i obshchestvennaya deyatel'nost' (1732 - 1799) / V. Chepinskii. Peterburg: Tipografiya Vysochaishe utverzhd. tovarishchestva "Obshchestvennaya pol'za", 1898. - 96 s.

5. Pyl'tsina, M.V. Pravovoi status regional'nykh sel'skokhozyaistvennykh obshchestv Rossiiskoi imperii v pervoi polovine XIX v. / M.V. Pyl'tsina // Vestnik VGAU. - 2011. - Vyp. 3. - S. 188-190.

6. Trudy Imperatorskogo Vol'nogo ekonomicheskogo obshchestva. T. 1. - S. - Peterburg: Tip. V. Demakova, 1894. - 191, 82, 6 s.

7. Tverskoi, P.A. Ministerstvo zemledeliya v Soedinennykh Shtatakh / P.A. Tverskoi // Vestnik Evropy. - 1895. - Vyp.6. - S. 651-669.

8. Lange, M. Avraam Linkol'n i velikaya bor'ba mezhdu severnymi i yuzhnymi amerikanskimi shtatami. Perev. s nem. / M. Lange. - S. Peterburg: Tipografiya Kukol-Yasnopol'skogo, 1867. - 474 s.

9. Stechkin, N.Ya. Severnye siyaniya. Zapiski druzei Rossii, ee derzhavnogo vozhdya vernopoddannykh / N.Ya. Stechkin. - Leiptsig: Tip. Bera i Germanna, 1882. - 173, 93 s.

10. Biryukovich, V. Upovaniya i somneniya / V. Biryukovich // Vestnik Evropy. - 1894. - Vyp. 6. - S. 791-808.

11. Mizhuev, P.G. Velikii raskol anglosaksonskoi rasy. Amerikanskaya revolyutsiya / P.G. Mizhuev. - S. - Peterburg: Izd. L.F. Panteleeva, 1901. - 252 s.

12. Borisenkov A.A. Ponyatie obshchestvennoi vlasti v sovremennoi rossiiskoi konstitutsii // Pravo i politika. - 2013. - 13. - C. 1786 - 1795. DOI: 10.7256/1811-9018.2013.13.10371. 